\title{
Congenital rubella after previous maternal immunity
}

B D Das, P Lakhani, J B Kurtz, N Hunter, B E Watson, K A V Cartwright, E O Caul, A P C H Roome

\begin{abstract}
Two mothers who had asymptomatic rubella infection in pregnancy gave birth to severely affected infants. In both, the presence of preexisting antibody was well documented, although it could not be established whether it was the result of vaccine or natural infection.
\end{abstract}

Rubella infection in women with previous immunity is common, but is not considered to carry a serious risk of clinical illness or fetal damage. Cases of such reinfection in which viraemia occurs are excessively rare. There are now, however, a small number of well documented cases in which rubella infection in women with immunity induced by vaccination has led to the birth of severely disabled infants. The subject has been reviewed by MorganCapner, ${ }^{1}$ and Best et al have recently investigated five cases. ${ }^{2}$

We present two further cases of rubella infection in pregnancy in which previous immunity had been well documented. Both maternal infections were asymptomatic, but resulted in the birth of abnormal infants infected with rubella. One woman had been vaccinated, but in neither case could we establish whether the rubella antibody had been induced by vaccination or by natural infection.

\section{Department of Microbiology, Milton Keynes General Hospital B D Das \\ P Lakhani}

Public Health

Laboratory,

John Radcliffe Hospital, Oxford

J B Kurtz

\section{Department of}

Paediatrics,

Gloucester Royal

Infirmary

N Hunter

B E Watson

K A V Cartwright

Regional Public Health and District Virus

Laboratory, Public

Health Laboratory,

Myrtle Road,

Kingsdown,

Bristol BS2 8EL

E O Caul

A P C H Roome

Correspondence to:

Dr Roome.

Accepted 7 December 1989

(Arch Dis Child 1990;65:545-6)

\section{Case reports}

CASE 1

An infant girl, born on 10 November 1987, was the first child of a 32 year old woman. The pregnancy was uneventful, rubella antibodies being detected on routine testing by radial haemolysis at 10 weeks. (Radial haemolysis does not distinguish between antibodies resulting from old infection or vaccination and recent infection.) At birth the baby weighed $2340 \mathrm{~g}$ and was 11 days postmature. There was a severe petechial rash covering the face, body, and limbs and the liver was enlarged. The eyes were thought to be small. The platelet count was $117 \times 10^{9} / 1$. Results of a lumbar puncture were normal except for a protein concentration of $1.46 \mathrm{~g} / \mathrm{l}$. Intrauterine infection was diagnosed.

Immediate postnatal problems included seizures, which were treated with phenobarbitone and a group B streptococcal septicaemia, which was treated with benzylpenicillin and gentamicin.

Further investigations confirmed microphthalmia and cataract of the left eye, and showed irregular calcification in the metaphyses of the long bones. A cardiac murmur was also detected but the heart was not investigated in detail. The baby had not smiled by the age of 10 weeks.

A cord blood sample had a rubella haemagglutination inhibition (HAI) antibody titre of 32 and rubella specific IgM was detected by $\mu$ capture enzyme linked immunosorbent assay (ELISA).

Serology for toxoplasma, cytomegalovirus, and syphilis showed no signs of infection. Retesting of maternal antenatal serum in parallel with maternal serum obtained on the day of delivery showed the following results: rubella antibody HAI on 1 April 1987 was 128, and on 10 November 1987 was 64. The serum was positive and negative for rubella IgM antibody on the same two dates, respectively. Rubella virus was cultured from a throat swab taken from the baby on 6 January 1988 .

On close questioning the mother did not recall having a rash during the pregnancy or any contact with rubella infection, but even in patients with congenitally affected babies up to a quarter will have no clinical symptoms, and reinfection is usually subclinical. ${ }^{2}$ She had been immunised against rubella in 1979, the date being recorded in the general practitioner's notes. In March 1984 she was shown to be immune to rubella by radial haemolysis during the course of investigations for infertility.

CASE 2

An infant boy was born at full term on 12 March 1987 to a healthy 26 year old woman after a normal delivery. At five weeks' gestation her husband and three children had been diagnosed as having rubella, but unfortunately no virological investigations were carried out on her. It is standard practice to investigate illnesses associated with rashes in pregnancy irrespective of whether the mother has had rubella or been vaccinated, not only becase of the possibility of reinfection but also because of the possibility of other virus infections, especially parvovirus B19. During each of her three normal pregnancies in 1982, 1983, and 1985 (which resulted in three normal deliveries at full term) the mother had been shown to be immune to rubella by radial haemolysis. No record could be found of her being vaccinated against rubella. She remained completely free of symptoms.

She became concerned about the possible effects on the fetus, and consulted her general practitioner at 16 weeks' gestation. At this time her rubella $\mathrm{HAI}$ titre was $1 / 320$ with a negative IgM by $\mu$ capture ELISA. A negative IgM concentration at this time interval does not exclude rubella reinfection at five weeks' gesta- 
tion. IgM does not reliably persist for more than six weeks after a primary infection, let alone a reinfection where only small amounts of $\operatorname{IgM}$ may be produced. The pregnancy proceeded uneventfully thereafter.

The baby weighed $2010 \mathrm{~g}$ at birth (below the third centile); his length was also below the third centile, and the head circumference just above it. At 2 months of age he had a dense right sided cataract associated with a right microphthalmia, signs of a small ventricular septal defect, hepatosplenomegaly, and profound sensorineural deafness confirmed by electrocochleography and brainstem evoked response audiometry. He was hypertonic with marked head lag and showed signs of delayed development. His head circumference had fallen below the third centile.

A blood sample from the baby at 10 weeks was strongly positive for rubella IgM antibody, and negative for cytomegalovirus and toxoplasma antibody.

\section{Discussion}

Both the cases described above represent proved subclinical rubella infections in previously immune pregnant women, which resulted in adverse outcomes. This confirms the work of others, ${ }^{12}$ that such infections do not have to be clinically apparent to harm the fetus. In neither mother were we able to establish whether their infection occurred after immunity that had been acquired naturally or after vaccination. We did have a report of vaccination in 1979 for the first mother, but no knowledge of any previous vaccination or infection.

If these cases were reinfections it is possible that the quality of antibody produced in women in whom seroconversion has occurred after vaccination may be inadequate for total protection compared with that induced by natural infection. If this is the case we can expect more reinfections with rubella that will produce fetal damage while natural rubella virus is still circulating, despite the recent introduction of the measles, mumps, rubella (MMR) vaccine. Harcourt $e t a l,{ }^{3}$ for example, found significant differences in rubella specific IgG, IgA, and IgM responses on subsequent challenge with rubella vaccine between volunteers in whom previous immunity had been induced by vaccine and those who had natural immunity.

Although O'Shea et al found that only one of 19 volunteers with low concentrations $(<15$ IU) of pre-existing immunity induced by rubella vaccine, and none of 12 with previous low natural immunity, had detectable viraemia after intranasal challenge with RA27/3 rubella virus vaccine, ${ }^{4}$ it is possible that this low incidence of viraemia might increase when the challenge is with natural virus.

Prospective surveillance of congenital rubella infections and their association with previous maternal immunisation will therefore need to be continued for many years to come.

Further studies are also indicated to determine the risks to the fetus, however small, in infections where there is previous antibody resulting from vaccination. We must, however, stress that rare events such as these should not detract from vigorous advocacy of the MMR vaccine.

1 Morgan-Capner P. Does rubella reinfection matter? In: Mortimer PP, ed. Public Health Virology 12 reports. London: Public Health Laboratory Service, 1986:50-62.

2 Best JM, Banatvala JE, Morgan-Capner P, Miller E. Fetal infection after maternal reinfection with rubella: criteria for defining reinfection. Br Med $\mathcal{f}$ 1989;299:773-5.

3 Harcourt GC, Best JM, Banatvala JE. Rubella specific serum and nasopharyngeal antibodies in volunteers with naturally acquired and vaccine-induced immunity after intranasal challenge. I Infect Dis 1980;142:145-55.

4 O'Shea S, Best JM, Banatvala JE. Virus excretion and antibody response after challenge in volunteers with low levels of antibody to rubella virus. $\mathcal{F}$ Infect Dis 1983;148: 639-47.

\section{Department of Paediatrics, Raigmore Hospital, Inverness \\ G Stewart \\ G Farmer \\ Correspondence to: Dr G Farmer, \\ Department of Child Health, Aberdeen University Medical School, \\ Foresterhill \\ Aberdeen AB 2ZB. \\ Accepted 4 January 1990}

(ArchDis Child 1990;65:546-7)

\title{
Sturge-Weber and Klippel-Trenauny syndromes with absence of inferior vena cava
}

\author{
G Stewart, G Farmer
}

\begin{abstract}
A baby girl born at 33 weeks' gestation weighing $2250 \mathrm{~g}$ presented with Sturge-Weber syndrome, features of the Klippel-Trenauny syndrome, and absence of the inferior vena cava. We suggest that aplasia of the vena cava may be a feature of Klippel-Trenauny syndrome when the capillary malformation affects the trunk.
\end{abstract}

We report a case of Sturge-Weber syndrome with extensive capillary malformation over the trunk and features of Klippel-Trenauny syndrome, together with congenital absence of the inferior vena cava. There is to our knowledge only one previous report of Sturge-Weber syndrome (associated with an anomalous (double) inferior vena cava) and in this instance there were also features of Klippel-Trenauny syndrome. ${ }^{1}$

The Klippel-Trenauny syndrome can be associated with anomalies of the deep venous drainage of the limbs, including aplasia and duplication. ${ }^{2}$ Servelle, in his extensive experience of 786 cases with Klippel-Trenauny syndrome and venous malformations, encountered four cases with aplasia of the lower portion of the inferior vena cava. ${ }^{3}$ 